\title{
Concomitant Risk Factor Profile for Non-Arteritic Anterior Ischaemic Optic Neuropathy
}

\author{
Jagdeep Singh Gandhi \\ Neuro-Ophthalmology Service, Royal Eye Hospital, Manchester, UK
}

Von Jagow and Kohnen [1] propose that adalimumab therapy resulted in optic neuropathy in their particular patient. However, given the case characteristics, their discussion remains only partially complete without considering a differential diagnosis of non-arteritic anterior ischaemic optic neuropathy (NAION).

A number of characteristics that advocate NAION are identifiable in their patient. These factors are (1) age, (2) a 'crowded' optic disc, (3) clinical appearance of the acute lesion, (4) type of visual field deficit, (5) hypertension, (6) antihypertensive therapy and (7) a possible improvement with steroid treatment. Given these confounding elements in the case, tumour necrosis factor inhibitor therapy could justifiably be interpreted as a coincidental detail. The pitfall of mistaking NAION for another supposed pathogenic process in the optic nerve has been described on several occasions in the literature [2].

As a vasculopathic entity, NAION is an infarction of the optic nerve head which usually occurs in middle-aged and older individuals. The age group affected most frequently is that between 50 and 70 years, and accordingly the patient in this report is aged 60. Hypertension is a major predisposing factor, with the risk profile being further exacerbated by antihypertensive therapy [3]. As such, in this patient's case there is a drug history comprised of two antihypertensive agents. Furthermore, biomicroscopy detected mild hypertensive retinopathy, thus denoting similar NAION-favouring arteriosclerotic changes within the optic nerve head [4].

Another prime NAION risk factor is the optic disc with a constitutionally small cup, referred to as 'the disc at risk'. This anatomical configuration is susceptible to developing infarction because, with an impairment of perfusion, such 'crowdedness' is a perfect environment for inciting a critical level of ischaemia within the optic nerve head [5]. Assessment of the magnified photograph in this report intimates the presence of such a 'disc at risk'.

Similarly, the visual deficit of NAION par excellence is that of an altitudinal-type scotoma, as seen in this case. This observation follows from the fact that only a subterritory within the microvasculature of the optic nerve head suffers infarction under the duress of sudden ischaemia. Consequently, the horizontal midline is found to be respected on perimetric testing, a sign similarly encountered in retinovascular occlusions. Additionally, the chance of second-eye involvement by NAION has been reported at $25 \%$ over 3 years in a large series [6]. This point supports the finding in this patient of a small superior field defect in the contralateral eye, which may be the residue from a previous minor NAION unaccompanied by a symptomatic disturbance of visual acuity.

The authors also deduced an 'improvement of the patient's condition with treatment' following an increase in steroid dosage and commencement of other therapies. Where medical intervention is instituted in such a scenario, it is difficult to ascertain how much of the improvement results from treatment and how much is merely natural resolution. Since this argument offers the differential diagnosis of NAION, it is germane to highlight that systemic steroids can improve recovery of NAION when compared with no treatment [7].

Finally, to vindicate their observation, the authors make reference to anecdotal reports in the literature that have found a correlation between tumour necrosis factor inhibitor therapy and optic neuritis. However, in the present example clinical neuro-ophthalmologists will instantly appreciate that the risk factors also support a conclusion of NAION. Thus, the inference that optic neuropathy was invoked by tumour necrosis factor inhibitor therapy is difficult to reconcile with the conspicuous NAION risk profile also coexistent in this patient.

\section{KARGER}

Fax +4161306 1234 E-Mail karger@karger.ch www.karger.com
(C) 2009 S. Karger AG, Base 0030-3755/09/2233-0217\$26.00/0

Accessible online at:

www.karger.com/oph
Dr. Jagdeep Singh Gandhi, BSc, MB ChB, MRCS, MRCOphth

Neuro-Ophthalmology Unit, Royal Eye Hospital

Oxford Road

Manchester M13 9WH (UK)

Tel. +44 161276 1234, Fax +44 161276 5526, E-Mail doctorjsg@gmail.com 


\section{References}

1 von Jagow B, Kohnen T: Anterior optic neuropathy associated with adalimumab. Ophthalmologica 2008;222:292-294.

$\checkmark 2$ Gandhi JS: Sildenafil-associated NAION. Ophthalmology 2003;110:1860-1861.

>3 McCulley TJ, Lam BL, Feuer WJ: A comparison of risk factors for postoperative and spontaneous nonarteritic anterior ischaemic optic neuropathy. J Neuroophthalmol 2005; $25: 22-24$.
4 Hayreh SS: Blood flow in the optic nerve head and factors that may influence it. Prog Retina Eye Res 2001;20:595-624.

5 Beck RW, Servais GE, Hayreh SS: Anterior ischaemic optic neuropathy. IX. Cup-to-disc ratio and its role in pathogenesis. Ophthalmology 1987;94:1503-1508.
-6 Beri M, Klugman MR, Kohler JA, Hayreh SS: Anterior ischemic optic neuropathy. VII. Incidence of bilaterality and various influencing factors. Ophthalmology 1987;94:10201028

7 Hayreh SS, Zimmerman MB: Non-arteritic anterior ischemic optic neuropathy: role of systemic corticosteroid therapy. Graefes Arch Clin Exp Ophthalmol 2008;246:10291046.

\title{
Reply
}

\author{
Burkhard von Jagow ${ }^{a}$ Thomas Kohnen ${ }^{a, b}$ \\ a Department of Ophthalmology, Johann Wolfgang Goethe University, Frankfurt am Main, Germany; \\ ${ }^{b}$ Cullen Eye Institute, Baylor College of Medicine, Houston, Tex., USA
}

We thank Dr. Gandhi for his excellently presented comment on our case report. Additional discussion on the validation of clinical features and parameters in complex clinical cases is always welcome and constitutes the most exciting side of academic medicine.

Dr. Gandhi states that the risk profile and the clinical characteristics of our patient strongly support nonarteritic ischemic optic neuropathy. We agree that there were multiple risk factors in our patient that could evoke a number of differential diagnoses.

Dr. Gandhi emphasizes the altitudinal pattern of the visual field defect and the prevalence of a 'disk at risk' which he says to have identified on the delivered photo. However, the scotoma in our patient did not respect the horizontal line as would be typical of an altitudinal defect. Furthermore, we found no signs of a crowded disk such as small disk diameter $(2.9 \mathrm{~mm})$ or drusen in ultrasound examination.

The case series on the association of tumor necrosis factor $\alpha$ antagonists and papillitis that we cited in our report belong to the lowest level of evidence-based medicine. Therefore, Dr. Gandhi has the right to nickname them 'anecdotal'. However, there is a growing awareness and concern of uveitis specialists (expressed on uveitis conferences) about the demyeliating potential of these agents, which surpasses the growing number of cases reported in the literature. This is the case especially for etanercept [1].
The relative coincidence of the optic neuropathy with the start of adalimumab and the fast recovery after discontinuation of the drug make the association of the pathology with the agent most probable.

\section{Reference}

1 Lim LL, Fraunfelder FW, Rosenbaum JT: Do tumor necrosis factor inhibitors cause uveitis? A registry-based study. Arthritis Rheum 2007;56:3248-3252.

Thomas Kohnen, MD, Prof. of Ophthalmology Johann Wolfgang Goethe University Department of Ophthalmology

Theodor-Stern-Kai 7

DE-60590 Frankfurt am Main (Germany) Tel. +4969630 16739, Fax +496963013893

E-Mailkohnen@em.uni-frankfurt.de 